OPEN ACCESS

Edited by:

Massimiliano Fenice,

University of Tuscia, Italy

Reviewed by:

Maria Bogomilova Angelova,

The Stephan Angeloff Institute

of Microbiology, Bulgarian Academy

of Sciences, Bulgaria

Anna Maria Garzillo,

University of Tuscia, Italy

Khelifa Bouacem,

Mouloud Mammeri University of Tizi

Ouzou, Algeria

*Correspondence:

Chunyu Yang

ycy21th@sdu.edu.cn

Specialty section:

This article was submitted to

Extreme Microbiology,

a section of the journal

Frontiers in Microbiology

Received: 28 June 2020 Accepted: 26 February 2021

Published: 18 March 2021

Citation:

Dong X, Wang W, Li S, Han H,

Lv $P$ and Yang C (2021)

Thermoacidophilic Alicyclobacillus

Superoxide Dismutase: Good

Candidate as Additives in Food

and Medicine.

Front. Microbiol. 12:577001. doi: 10.3389/fmicb.2021.577001

\section{Thermoacidophilic Alicyclobacillus Superoxide Dismutase: Good Candidate as Additives in Food and Medicine}

\author{
Xueqian Dong ${ }^{1,2}$, Wei Wang', Shannan $\mathrm{Li}^{1}$, Hongyu Han${ }^{2}$, Peiwen $\mathrm{Lv}^{1}$ and Chunyu Yang ${ }^{1 \star}$ \\ 1 State Key Laboratory of Microbial Technology, Institute of Microbial Technology, Shandong University, Qingdao, China, \\ ${ }^{2}$ Shandong Food Ferment Industry Research \& Design Institute, QiLu University of Technology (Shandong Academy \\ of Sciences), Jinan, China
}

Thermoacidophilic Alicyclobacillus strains attract great interests as the resource of thermostable or acidic enzymes. In this study, a putative gene encoding superoxide dismutase (AaSOD) was identified in a thermoacidophilic Alicyclobacillus strain. With a 16-fold activity observed, the AaSOD activity expressing in the medium of manganese enrichment was much higher than that in the iron medium. In addition, the purified AaSOD can be reconstituted exclusively with either $\mathrm{Fe}^{2+}$ or $\mathrm{Mn}^{2+}$, with its $\mathrm{Mn}$-bound protein showing 25-fold activity than that of Fe-bound form. The optimal temperature for AaSOD reaction was $35^{\circ} \mathrm{C}$, and was highly stable at any certain temperature up to $80^{\circ} \mathrm{C}$. Of particular interest, the enzyme is found to be very stable across a wide $\mathrm{pH}$ range spanning from 2.0 to 10.0 , which confers its robust stability in the acidic stomach environment and implies striking potentials as food additive and for medical use.

Keywords: thermoacidophilic Alicyclobacillus strain, superoxide dismutase, acid tolerant, thermostability, cambialistic $\mathrm{Fe} / \mathrm{Mn}$ type

\section{INTRODUCTION}

Superoxide dismutases (SODs, EC 1.15.1.1) are one type of antioxidant enzymes derived from living organisms which can protect themselves against oxidative stress, by achieving disproportionation of superoxide anion radical $\left(\mathrm{O}_{2}{ }^{-}\right)$to hydrogen peroxide $\left(\mathrm{H}_{2} \mathrm{O}_{2}\right)$ and dioxygen $\left(\mathrm{O}_{2}\right)$ through a redox cycle of metal ions (Abreu and Cabelli, 2010). SODs have been confirmed to be closely related to various physiological processes in living bodies, since they are related not only to the prevention and treatment of various diseases, but also to anti-aging therapy and prevention of skin pigmentation. SODs, also known as metalloenzymes, are divided into four groups depending on their metal preferences: manganese SOD (Mn-SOD), iron SOD (Fe-SOD), copper/zinc SOD (Cu/Zn-SOD), and nickel SOD (Ni-SOD) (Perry et al., 2010; Bafana et al., 2011). The resolved crystal structures of different types of SODs revealed that these proteins differ not only with regard to the coordinated metal ion, but also to the protein folding. $\mathrm{Mn}$-SOD and Fe-SOD are closely related when compared by their amino acids and tertiary structures, and assigned into one family (Miller, 2012). In this family, some use both $\mathrm{Fe}^{2+}$ and $\mathrm{Mn}^{2+}$ as their cofactors, and thus are referred to as the cambialistic Fe/Mn type SODs (Schmidt et al., 1996; Yamano et al., 1999). In spite of metal ion specificity, 
these Fe-SODs, Mn-SODs, and the cambialistic SODs were found to be phylogenetically related, which is proved by the high sequence identity, as well as many common features in their tertiary structures (Jackson and Cooper, 1998). In strain Escherichia coli, the Mn-SOD and Fe-SOD are extremely similar in sequence (45\% identity) and crystal structure ( $91 \%$ homology), but are strictly specific to their cognate metal ions (Hunter et al., 2018). The cambialistic SODs can accommodate both $\mathrm{Fe}^{2+}$ and $\mathrm{Mn}^{2+}$ as their cofactors for catalysis but display different ions preference. ApeSOD from Aeropyrum pernix is less active in its Fe-bound form while the cambialistic SOD from Propionibacterium shermanii exhibits similar enzymatic activity in the presence of $\mathrm{Fe}^{2+}$ and $\mathrm{Mn}^{2+}$ (Meier et al., 1982; Nakamura et al., 2011). Comparison of the crystal structures of both SODs shows that these two cambialistic SODs have different binding forms with $\mathrm{Fe}^{2+}$ and $\mathrm{Mn}^{2+}$, which was proposed as a structural explanation for their ions preference (Schmidt et al., 1996; Nakamura et al., 2011).

Supplementation of exogenous SOD has been reported to boost the antioxidant defense of host (Manolov et al., 2017). Considerable evidences from clinical or animal models have been accumulated and revealed that SOD is beneficial in a wide variety of applications, including reduction fibrosis following radiation treatment, preventions of aging, diabetes, tumor formation, and hepatitis $\mathrm{C}$ related fibrosis (Matès and Sánchez-Jimènez, 2000; Emerit et al., 2006; Bafana et al., 2011; Naso et al., 2011), or reduction of the cytotoxic and cardiotoxic effects of anticancer drugs (Trotti, 1997). Due to its excellent antioxidant and therapeutic properties, various SOD products have been applied in the industries of medicine, health care products, food additives, and cosmetics (Johnson and Giulivi, 2005). However, the thermal denaturation is an important factor leading to enzyme inactivation because the high temperature treatment is often processed in practical applications of the enzyme (Song et al., 2009). Therefore, it has stimulated a widespread interest in exploring thermotolerant enzymes from thermophilies (Morozkina et al., 2010). A plenty of previous research confirmed that the thermostable enzymes have unique structural and functional characteristics that give them good adaptability in high temperature environment. To date, SODs have been identified from various thermophilic archaea and bacteria, including Bacillus (Boyadzhieva et al., 2010), thermoacidophilic crenarchaeon (Slutskaya et al., 2012), Pyrobaculum (Amo et al., 2003), Chloroflexus (Lancaster et al., 2004), Thermus species (Mandelli et al., 2013) and so on. In addition, SODs from thermophilic fungi have also been reported by a few studies, such as Thermomyces lanuginosus Mn-SOD (Li et al., 2005) and Thermoascus aurantiacus var. levisporus $\mathrm{Cu} / \mathrm{Zn}-\mathrm{SOD}$, which also display remarkable tolerance to the extreme temperature (Song et al., 2009). Besides these wild type thermophilic SODs, thermostable SODs were also constructed by engineering protocols. The heat-resistance and stress-tolerance of thermophilic cambialistic Fe/Mn-SOD from A. pernix K1 was successfully developed through the fusion with the N-terminal domain of Geobacillus thermodenitrificans SOD (Li et al., 2017).

Comparing with its thermostability, the acidic tolerance of SOD is far less addressed, since few species of SOD are enzymatically stable under extremely acidic conditions (Ken et al., 2005). Alicyclobacillus strains are heterotrophic organisms that mostly inhabit acidic geothermal environments such as hot springs and acid mine waters (Zhang et al., 2015; López et al., 2018). As an extraordinary resource for exploring unique enzymes with acidophilic and (or) thermophilic properties, the Alicyclobacillus isolates are of great interests in recent years because of their double physiological characteristics of acidophilic and thermotolerant (McKnight et al., 2010). Some thermostable and acidic tolerant glycoside hydrolases, including $\alpha$-amylase (Zhang et al., 2018), glucanase (Bai et al., 2010), xylanase (Lee et al., 2018) etc., have been identified from Alicyclobacillus species. Correa-Llantén et al. (2014) have purified SOD from Alicyclobacillus isolate CC2 that was most active at $55^{\circ} \mathrm{C}, \mathrm{pH}$ 7.4. However, there are no further studies performed on Alicyclobacillus-derived SOD. In the present study, we engaged in exploring a novel SOD from a strain Alicyclobacillus sp. HJ previously isolated from the hot-spring (Zhang et al., 2018). As a result, the Fe/Mn-SOD with remarkable acid and thermal tolerance was identified and catalytically characterized in this study.

\section{MATERIALS AND METHODS}

\section{Strains and Plasmids}

Strain Alicyclobacillus sp. HJ was isolated from Tengchong hotspring, Yunnan, China and deposited in the Marine Culture Collection of China (MCCC 1K03506). The 16S rDNA sequence analysis revealed $100 \%$ similarity with gene of Alicyclobacillus acidocaldarius DSM451. In the M63 medium, the strain grows optimally at conditions of $65^{\circ} \mathrm{C}$ and $\mathrm{pH} 4.0$ (Zhang et al., 2018). The clone vector pEASY-blunt and E. coli DH5 $\alpha$ was used for gene cloning and fidelity confirmation. The recombinant expression vector pET-24a(+) with AaSOD encoding gene was transformed into E. coli BL21 CodonPlus for protein expression, and Luria-Bertani (LB) medium was used for the cultivation of recombinants.

\section{Phylogenetic Analysis of AaSOD and Modeling}

The amino acid sequence of AaSOD were submitted to National Center for Biotechnology Information (NCBI) for blast analysis. A phylogenetic tree was constructed to establish the evolutionary relationship among AaSOD and corresponding SOD sequences retrieved from the NCBI protein database. MEGA 7.0 software was used to build the phylogenetic tree, by using NeighborJoining method with bootstrap replications of 1,000 (Kumar et al., 2016). Amino acid sequences multiple alignment was performed by ClustalX 2.0 and DNAMAN programs. The protein sequence of AaSOD was submitted to SWISS-MODEL server for homology modeling (Waterhouse et al., 2018).

\section{Protein Expression and Purification}

Genomic DNA of Alicyclobacillus sp. HJ was isolated with ChargeSwitch ${ }^{\circledR}$ gDNA Mini Bacteria Kit (Life Technologies) and 
used as template for AaSOD gene amplification. Primers for its PCR were designed as AaSOD-F ( $5^{\prime}$-CGGGATCCATGCCA CATCAACTCCCAC-3') and AaSOD-R (5' -CCCAAGCTTGC CGTTCAGCGCGGCCTCGT-3'), which incorporate restriction sites Bam HI and HindIII (underlined), respectively. The PCR products was ligated into $\mathrm{pET}-24 \mathrm{a}(+)$ and transformed in the competent cells E. coli BL21 CodonPlus. The correct clones were picked and further verified by PCR sequencing.

For AaSOD expression, cells of E. coli harboring pET-24a(+)AaSOD were cultured in $5 \mathrm{ml} \mathrm{LB}$ medium at $37^{\circ} \mathrm{C}$ for $12 \mathrm{~h}$. Subsequently, the culture was diluted at the ratio of 1:100 into $100 \mathrm{ml}$ fresh LB media containing $50 \mathrm{mg} \mathrm{l}^{-1}$ ampicillin and grown at $37^{\circ} \mathrm{C}, 180 \mathrm{rpm}$. When $\mathrm{OD}_{600}$ of the culture reached to 0.6 , isopropyl- $\beta$-D-thiogalactoside (IPTG) was added up to the final concentration of $0.5 \mathrm{mM}$ for protein induction. After cultivation at $18^{\circ} \mathrm{C}, 100 \mathrm{rpm}$ for $12 \mathrm{~h}$, cells were harvested by centrifugation at $8,000 \times g$ for $10 \mathrm{~min}$ at $4^{\circ} \mathrm{C}$. The cell debris was resuspended in $10 \mathrm{ml}$ buffer A $(20 \mathrm{mM}$ Tris$\mathrm{HCl}, 0.5 \mathrm{M}$ sodium chloride, $\mathrm{pH}$ 8.0) with a protease inhibitor cocktail and disrupted using a high-pressure homogenizer (ATS Engineering Inc., Canada). The cell lysis was then centrifuged at $17,000 \times g$ for $30 \mathrm{~min}$ at $4^{\circ} \mathrm{C}$, and the supernatant was applied to HisTrap ${ }^{\mathrm{TM}}$ FF crude column (GE Healthcare) for protein purification at $4^{\circ} \mathrm{C}$. The target protein was eluted with buffer A that contains $250 \mathrm{mM}$ imidazole. For further analysis, the elution was concentrated and dialyzed overnight with $50 \mathrm{mM}$ Tris- $\mathrm{HCl}$ buffer $(\mathrm{pH} 8.0)$ at $4^{\circ} \mathrm{C}$. The protein concentration was determined by Brad-Ford method with bovine serum albumin (BSA) as standard (Bradford, 1976). The expression level and purity of target protein were verified by SDS-PAGE $(12 \% \mathrm{w} / \mathrm{v})$, with Bio-Rad Mini-PROTEAN TETRA electrophores system (United States).

\section{SOD Activity Assay}

The superoxide dismutase activity was measured by pyrogallic acid spontaneous oxidation assay (Marklund and Marklund, 1974). Briefly, $50 \mathrm{mM}$ pyrogallic acid was added to $50 \mathrm{mM}$ Tris- $\mathrm{HCl}$ buffer $(\mathrm{pH} \mathrm{8.0)}$ at the final volume of $3 \mathrm{ml}$ reaction mixture. The absorbance of the mixture was then measured at $325 \mathrm{~nm}$ at every $30 \mathrm{~s}$, during a 4-min reaction process at room temperature. The rate of the self-oxidation was approximately

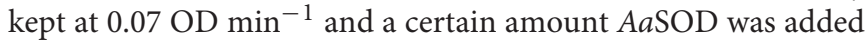
to the reaction mixture at an inhibition ratio of $50 \%$. One unit of superoxide dismutase activity was defined by the amount of enzyme that inhibited the rate of pyrogallic acid spontaneous oxidation by $50 \%$. The activities of each sample were performed in three replicates.

\section{Influence of $\mathrm{Fe}^{2+}$ and $\mathrm{Mn}^{2+}$ on the Native Protein Expression}

The E. coli strain carrying pET-24a(+)-AaSOD was prepared as above described and then inoculated into $100 \mathrm{ml} \mathrm{LB}$ medium, or $\mathrm{LB}$ media containing $1 \mathrm{mM} \mathrm{FeCl}, \mathrm{MnCl}_{2}$, or both ions. After IPTG induction for $12 \mathrm{~h}$, cells were collected by centrifugation and lysed in high-pressure homogenizer. After centrifugation, the supernatant flowed through the HisTrap crude column for protein purification and then the activity of SOD was measured by standard procedures described above.

\section{Reconstitution of Metals Into SOD}

The apo-enzyme was prepared as previous described (He et al., 2007). In brief, the enzyme was dialyzed with $50 \mathrm{mM}$ acetate buffer ( $\mathrm{pH}$ 3.8) containing $8 \mathrm{M}$ urea and $10 \mathrm{mM}$ EDTA for $16 \mathrm{~h}$ at room temperature. Then the enzyme was dialyzed at $4^{\circ} \mathrm{C}$ sequentially with $50 \mathrm{mM}$ acetate buffer ( $\mathrm{pH} 3.8$ ) containing $8 \mathrm{M}$ urea, $50 \mathrm{mM}$ Tris- $\mathrm{HCl}$ buffer ( $\mathrm{pH} 7.0)$ containing $8 \mathrm{M}$ urea, and $50 \mathrm{mM}$ Tris-HCl buffer ( $\mathrm{pH} 8.0$ ). To prepare $\mathrm{Mn}$ - or Fereconstituted $A a S O D$, the apo-protein was subsequently dialyzed for $4 \mathrm{~h}$ at $4^{\circ} \mathrm{C}$ with the following buffers: $8 \mathrm{M}$ urea, $50 \mathrm{mM}$ acetate buffer, $10 \mathrm{mM} \mathrm{MnSO}_{4}$ and (or) $\mathrm{FeSO}_{4}$, pH 3.8; $8 \mathrm{M}$ urea, $50 \mathrm{mM}$ phosphate buffer, $10 \mathrm{mM} \mathrm{MnSO}_{4}$ and (or) $\mathrm{FeSO}_{4}, \mathrm{pH} 7.0 ; 4 \mathrm{M}$ urea, $50 \mathrm{mM}$ phosphate buffer, $10 \mathrm{mM} \mathrm{MnSO}_{4}$ and (or) $\mathrm{FeSO}_{4}$, $\mathrm{pH}$ 7.0; $2 \mathrm{M}$ urea, $50 \mathrm{mM}$ phosphate buffer, $10 \mathrm{mM} \mathrm{MnSO}_{4}$ and (or) $\mathrm{FeSO}_{4}, \mathrm{pH} 7.0 ; 50 \mathrm{mM}$ phosphate buffer, $1 \mathrm{mM} \mathrm{MnSO}_{4}$ and (or) $\mathrm{FeSO}_{4}$, $\mathrm{pH} 7.0$; and $50 \mathrm{mM}$ Tris- $\mathrm{HCl}$ buffer/0.5 mM EDTA, $\mathrm{pH}$ 8.0, respectively. The reconstituted enzymes obtained were analyzed by SDS-PAGE and the specific activity was determined by pyrogallic acid spontaneous oxidation assay.

\section{Metal Analysis}

Inductively Coupled Plasma Mass Spectrometry (ICP-MS) was used to measure the contents of $\mathrm{Fe}^{2+}$ and $\mathrm{Mn}^{2+}$ Briefly, the mixture of $500 \mu \mathrm{l}$ sample $\left(1 \mathrm{mg} \mathrm{ml}^{-1}\right)$ and $8 \mathrm{ml} 65 \%$ nitric acid was digested by microwave digestion system. $\mathrm{ddH}_{2} \mathrm{O}$ was added to the mixture at a total volume of $10 \mathrm{ml}$ subsequently and further analyzed by ICP8000 ICP-OES. The $\mathrm{Fe}^{2+}$ and $\mathrm{Mn}^{2+}$ concentrations were calculated based on their corresponding standard curves. Under experimental conditions, the standard recovery rate is between $96.23-102.65 \%$ for $\mathrm{Fe}^{2+}$, and 98.31$103.05 \%$ for $\mathrm{Mn}^{2+}$.

\section{Effect of Temperature on AaSOD}

The optimum temperature was determined by measuring the activity of SOD at different temperatures ranging from 25 to $80^{\circ} \mathrm{C}$. For thermal stability measurement, $1 \mathrm{mg} \mathrm{ml} \mathrm{ml}^{-1}$ protein was incubated in $50 \mathrm{mM}$ Tris- $\mathrm{HCl}$ buffer $(\mathrm{pH} 8.0)$ at room temperature (RT), 60, 70, 80, 90, and $100^{\circ} \mathrm{C}$ for $1 \mathrm{~h}$, respectively. Subsequently, the residual activities were determined by the standard condition $\left(\mathrm{pH} 8.0,25^{\circ} \mathrm{C}\right)$ as described above. Each temperature was performed in triplicate. The relative activity was calculated by the percentage of the maximum activity at $35^{\circ} \mathrm{C}$.

After dialyzed overnight with $200 \mathrm{mM}$ HEPES (pH 8.0), the purified AaSOD was tested for its thermal denaturation in the MicroCal VP-DSC (Malven). Protein sample $\left(1 \mathrm{mg} \mathrm{ml}^{-1}\right)$ was stirred to degassed under vacuum, cooled down to $20^{\circ} \mathrm{C}$, and then gradually heated to $110^{\circ} \mathrm{C}$. Using the dialysis buffer as a baseline, AaSOD sample was scanned from a temperature range of 70 to $110^{\circ} \mathrm{C}$ at a rate of $1.5^{\circ} \mathrm{C} \mathrm{min}^{-1}$. By subtracting the baseline, the transition curve was fitted by non-2-state model and the $T_{m}$ value was calculated (MN2state) in the Origin software (MicroCal Software, Inc., Northampton, MA, United States). 


\section{pH Tolerance of AaSOD}

The $\mathrm{pH}$ stability of AaSOD was determined by incubating the enzyme in various buffers with different $\mathrm{pH}$ values at $25^{\circ} \mathrm{C}$ for $1 \mathrm{~h}$, and then measuring the residual activity under standard assay conditions described above. The buffer systems include $200 \mathrm{mM}$ KCl-HCl buffer ( $\mathrm{pH} 1.0-2.0)$, acetate buffer ( $\mathrm{pH} 2.0-5.0)$, sodium phosphate buffer ( $\mathrm{pH}$ 5.0-7.0), Tris- $\mathrm{HCl}$ buffer $(\mathrm{pH} 7.0-9.0)$, and glycine- $\mathrm{NaOH}$ buffer ( $\mathrm{pH} 9.0-10.0)$. Each experiment was performed in triplicate. The maximal activity of AaSOD was defined as $100 \%$ for relative activity calculation.

\section{Effects of Divalent Metal Ions on SOD Activity}

Effects of metal ions on AaSOD activity were determined by adding various divalent metal salts $\left(\mathrm{MgCl}_{2}, \mathrm{ZnSO}_{4}, \mathrm{BaCl}_{2}\right.$, $\mathrm{CaCl}_{2}, \mathrm{CuSO}_{4}, \mathrm{NiSO}_{4}, \mathrm{CoCl}_{2}, \mathrm{MnSO}_{4}$, and $\mathrm{FeSO}_{4}$ ), at a final concentration of $1 \mathrm{mM}$ in $50 \mathrm{mM}$ Tris- $\mathrm{HCl}$ buffer $(\mathrm{pH}$ 8.0). After incubating the purified AaSOD with each ion at $25^{\circ} \mathrm{C}$ for $30 \mathrm{~min}$, the activities were measured under the standard conditions. The activity of the enzyme without addition of metal ions was defined as $100 \%$ and used for relative activity calculation.

\section{Statistical Method}

The data was analyzed using origin 9.0 (OriginLab corp., United States), the means and standard deviations were calculated by descriptive statistics.

\section{Nucleotide Sequence Accession Number}

The nucleotide sequence encoding AaSOD was deposited in the GenBank database under accession number of MT559075.

\section{RESULTS AND DISCUSSION}

\section{Sequence Analysis and Structural Analyses of AaSOD}

Based on the genomic analysis of Alicyclobacillus sp. HJ, a putative 204 amino acid protein encoded by orf0188 was predicted to be involved in detoxifying superoxide radicals, converting them to hydrogen peroxide and oxygen. Blast analysis indicated that $A a S O D$ exhibits $72.5 \%$ identity with a Mn-SOD in Geobacillus stearothermophilus (Adams et al., 2019) and 69.7\% identity with the Mn-SOD in Bacillus subtilis 168 (Liu et al., 2007). As shown in Figure 1, AaSOD was phylogenetically clustered with some other identified Mn-SODs and the Fe/Mn SODs from Staphylococcus species, while relatively distant with the Fe-SOD proteins. As both $\mathrm{Mn}$ - and Fe-SODs from Pseudomonas aeruginosa PAO1 or E. coli $\mathrm{K} 12$ were blasted as homologs of AaSOD, the amino sequence of AaSOD showed $56.8 \%$ identity with that of Mn-SOD (Steinman, 1978) from E. coli $\mathrm{K} 12$, and also $48.3 \%$ with its Fe-dependent SOD (Carlioz et al., 1988). This firmly verified the conclusion that Fe- and MnSODs are highly conserved in sequences and three dimension (3D), while possessing different dependence to metal ions (Lah et al., 1995). Based on the multiple sequence alignment, the

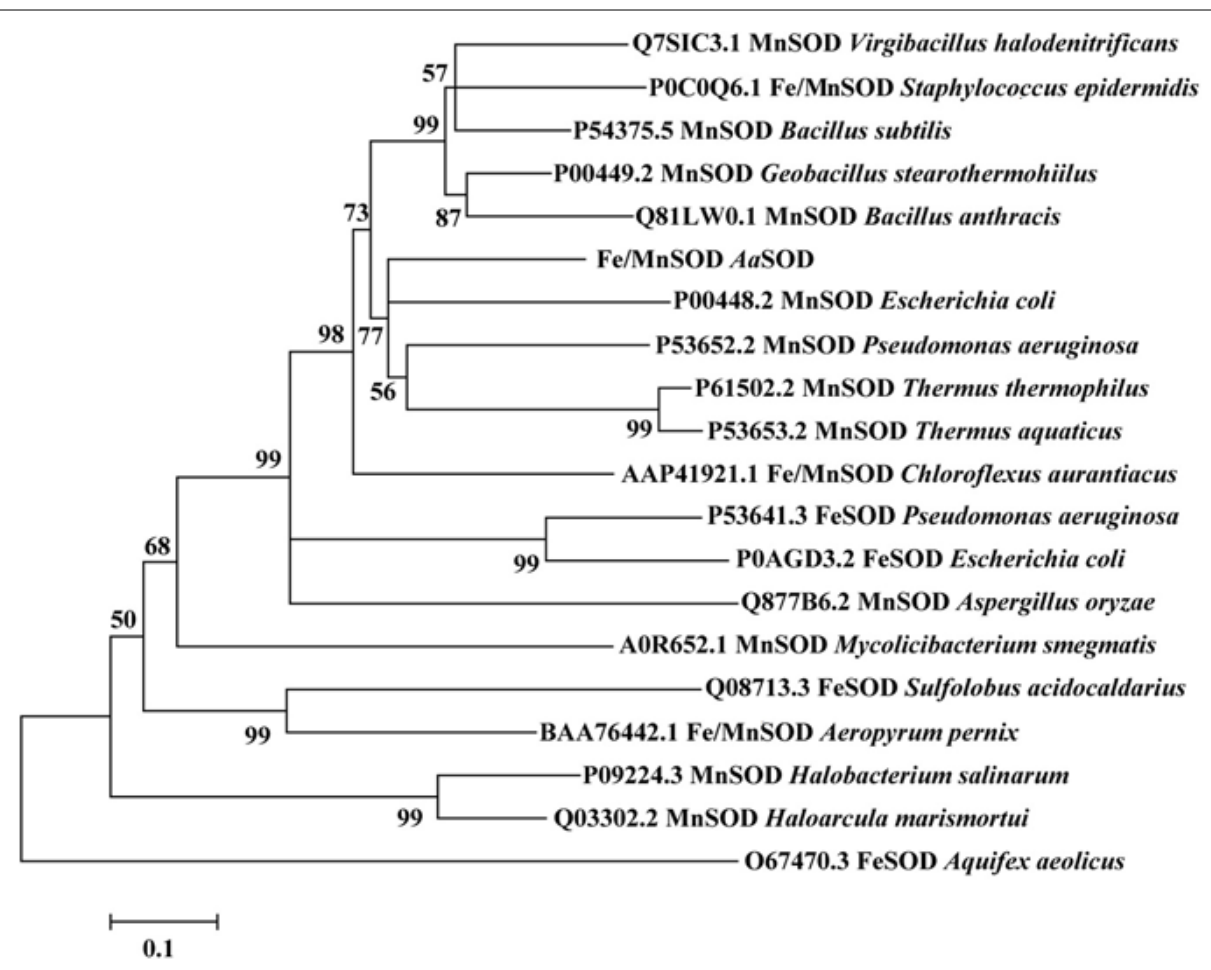

FIGURE 1 | Neighbor-joining phylogenetic tree based on the amino sequences of AaSOD and its closest relatives retrieved from NCBI database. The tree was built by the program MEGA version 7.0. Bootstrap percentages $>50 \%$ (based on 1000 replications) are shown at branch points. 


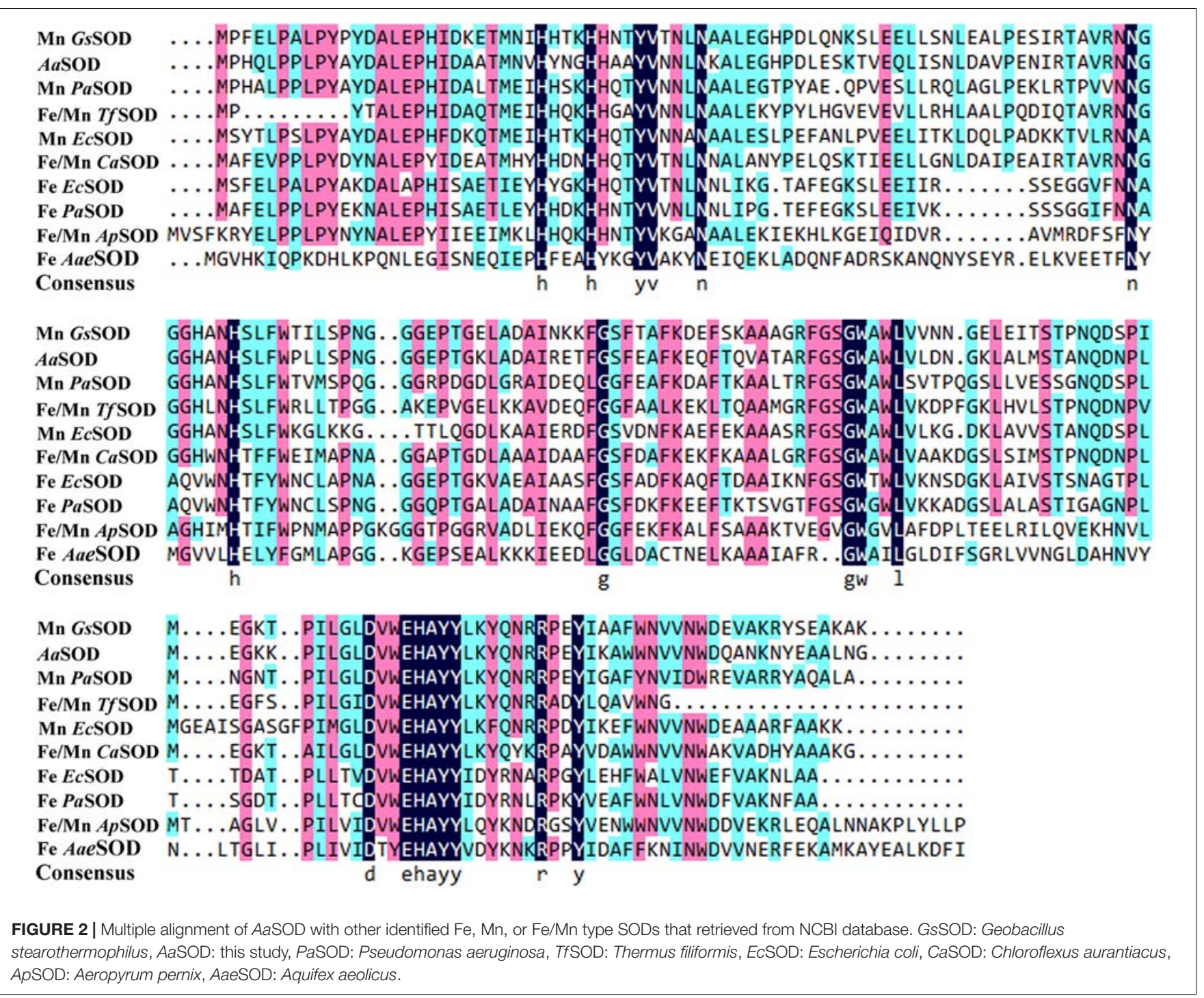

Mn- and Fe/Mn SODs share more conserved sequences as shown in Figure 2, while possessing more variations from our Fe SODs. Consequently, we assumed that the catalytic process of AaSOD may use $\mathrm{Mn}$ or $\mathrm{Fe} / \mathrm{Mn}$ as its cofactors.

A homology model of AaSOD was generated by the auto modeling system in the SWISS-MODEL server, based on the recently resolved structure of Gs-MnSOD (PDB: 6pro) as the template (Adams et al., 2019), which is from strain G. stearothermophilus and aligns $72.5 \%$ with the query sequence. As shown in Figure $\mathbf{3 A}$, the superimposition of the predicted 3D structure of AaSOD significantly conformed to the tertiary structure of $G s-M n S O D$. The four residues for manganese binding, His 26, His 81, Asp 163, and His 167, are all well conserved in the AaSOD sequence (Figure 2) and occupy identical spatial locations in its homologs structure (Figure 3B).

\section{Protein Purification}

To avoid the formation of inclusion body during protein expression process and gain high expression level, AaSOD was heterologous expressed in the E. coli host of BL21 Codonplus, which contains extra copies of the $\operatorname{argU}$, ileY, and leuW tRNA genes. In addition, the heterologous expression of AaSOD was induced at a low temperature of $18^{\circ} \mathrm{C}$. As a result, a large amount of SOD was produced after 10 -h induction by shaking at $100 \mathrm{rpm}$. As shown in Figure 4, a tense band of approximately $25 \mathrm{kDa}$ was detected in the SDS-PAGE, which is in accordance with the theoretical molecular weight of $22.82 \mathrm{kDa}$. After onestep purification on the His-Trap affinity column by $250 \mathrm{mM}$ imidazole elution, a high yield of $99.8 \mathrm{mg} \mathrm{l}^{-1}$ protein with high purity of $95 \%$ were obtained. We assumed that the high purification level and recovery rate would be benefit from the high expression levels of the protein. This confers AaSOD great potentials for scaled-up production and industrial applications. However, extracellular expression protocol could be needed for preparing AaSOD products considering its purification efficiency. To choose host strains that are suitable for extracellular protein expression, such as Bacillus subtilis, would be addressed in the $A a S O D$ production. 


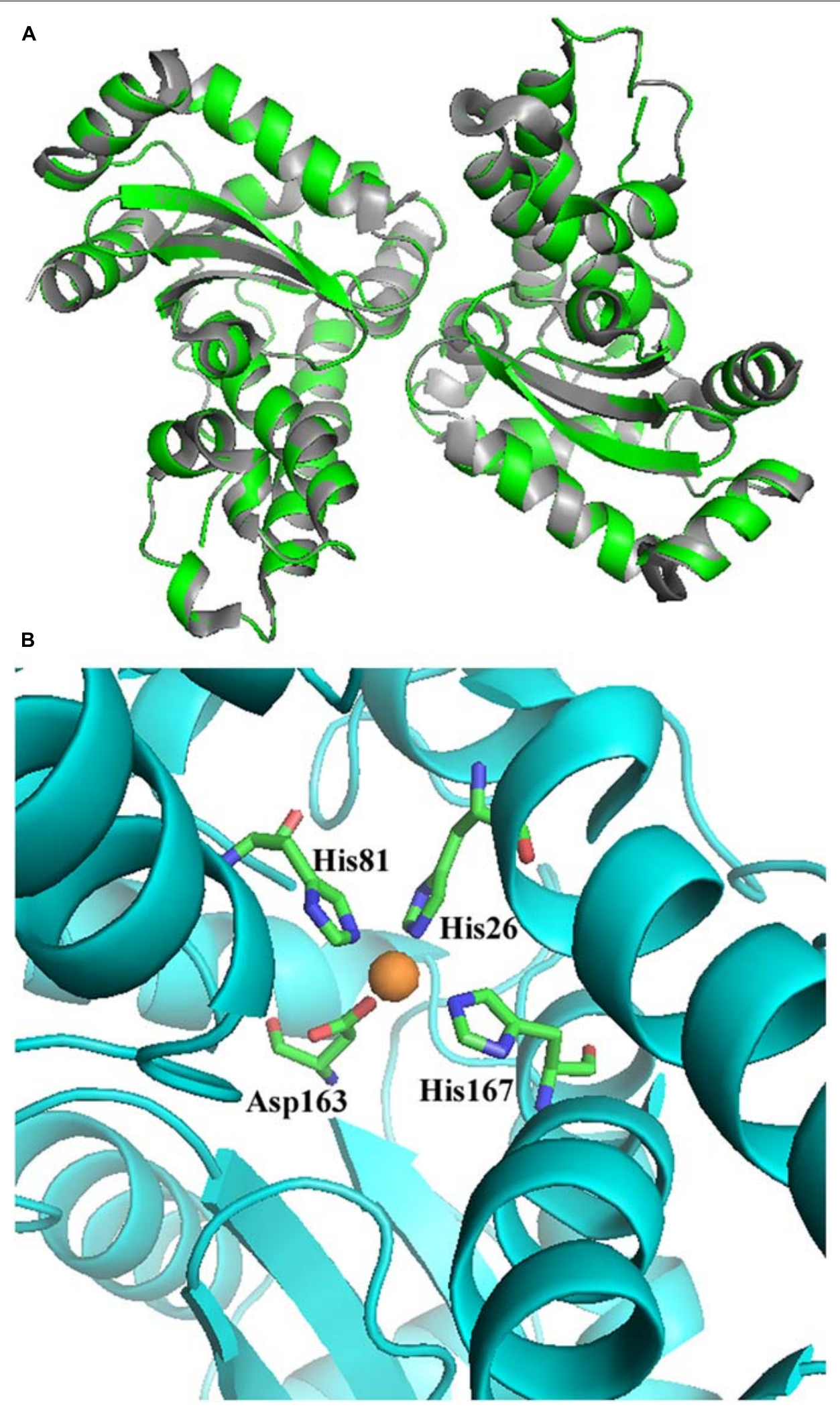

FIGURE 3 | Superimposition of the predicted structure of AaSOD (Green) over its template of Geobacillus stearothermophilus Gs-MnSOD (gray) (A) and four predicted residues for manganese binding (B). 


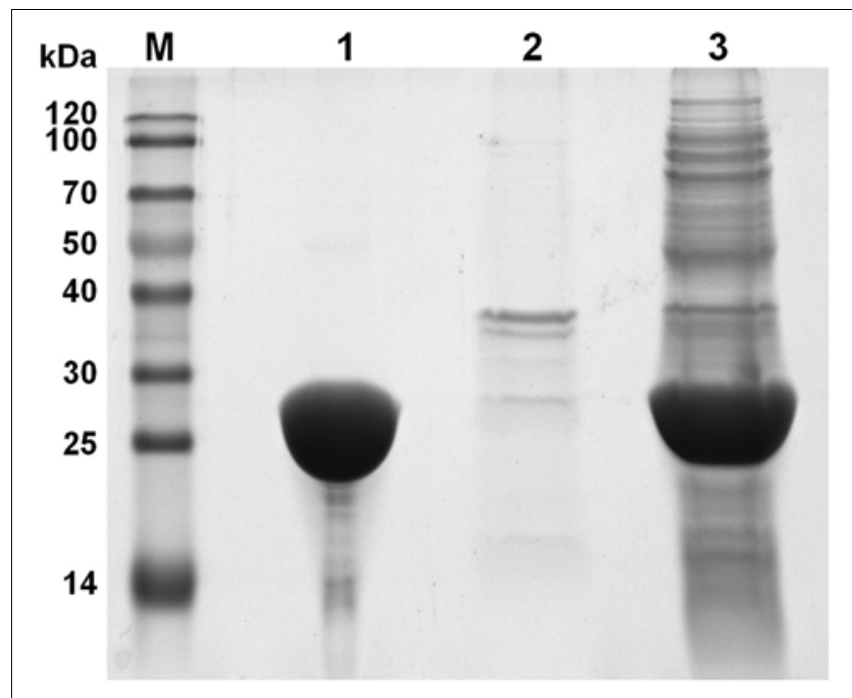

FIGURE 4 | SDS-PAGE spectrum of AaSOD. Lane M, Marker; lane 1, purified protein after His-Trap affinity column; lane 2, cell debris of the $E$. coli recombinant harboring $A a S O D$; lane 3 , supernatant of the $E$. coli recombinant harboring AaSOD induced by IPTG for $12 \mathrm{~h}$ at $18^{\circ} \mathrm{C}$.

\section{Metal Incorporation of AaSOD}

To explore the metal incorporation of $\mathrm{AaSOD}$ in its native form, $1 \mathrm{mM} \mathrm{MnSO}_{4}$ and (or) $\mathrm{FeSO}_{4}$ was added into $\mathrm{LB}$ medium during the expression process. As shown in Table 1, the proteins purified from the LB medium without ion supplementation (native protein) possessed a specific activity of $90.94 \mathrm{U} \mathrm{mg}^{-1}$, which is obviously higher than the apo-enzyme $\left(5.5 \mathrm{U} \mathrm{mg}^{-1}\right.$, Table 1). The fact is that the natural LB medium contains trace metal ions, and thus provides $\mathrm{Fe}^{2+}$ or $\mathrm{Mn}^{2+}$ to the AaSOD for cooperation. It was further confirmed by the presence of coordinated $\mathrm{Fe}^{2+}$ and $\mathrm{Mn}^{2+}$ in the ICP-MS analysis. In the natural $\mathrm{AaSOD}$, the $\mathrm{Fe}^{2+}$ and $\mathrm{Mn}^{2+}$ contents per one molar proteins were 0.051 and $6.85 \times 10^{-3} \mathrm{~mol}$, respectively. However, only $8.18 \times 10^{-4} \mathrm{~mol}$ of $\mathrm{Fe}^{2+}$ and $5.20 \times 10^{-5} \mathrm{~mol}$ of $\mathrm{Mn}^{2+}$ were detected in the apo-SOD. Different from the lower activity of proteins that expressed in the natural or $\mathrm{Fe}^{2+}$-rich LB medium, there was significantly higher AaSOD activity of $1198.55 \mathrm{U}$ $\mathrm{mg}^{-1}$ purified from the $E$. coli culture enriched with $1 \mathrm{mM}$ $\mathrm{MnSO}_{4}$. And AaSOD from the medium containing these two ions, displayed a modest activity of $534.56 \mathrm{U} \mathrm{mg}^{-1}$. Differently, the $\mathrm{Fe}^{2+}$-enriched cultures induced similar amount of AaSOD but with very low activity (74.65 $\left.\mathrm{U} \mathrm{mg}^{-1}\right)$, indicating that AaSOD is a cambialistic enzyme because of $\mathrm{Mn}^{2+}$ binding being much more effective than $\mathrm{Fe}^{2+}$ binding, and therefore should be assigned into $\mathrm{Fe} / \mathrm{Mn}$ type SOD. The activity bias between $\mathrm{Fe}$ and Mn-bound SOD was also identified in some thermostable SODs, in which their Fe-reconstituted SOD activity is much lower than that of Mn-reconstituted SOD (Li et al., 2016). For examples, the SOD from thermophilic C. aurantiacus was most efficient with manganese incorporated, up to $30 \%$ of the activity was retained with iron (Lancaster et al., 2004). What's more, the $\mathrm{MnSOD}_{c d}$ from Clostridium difficile exhibited the highest activity while Fe-sub-MnSOD $c d$ showed only 1/10 activity of
$\mathrm{MnSOD}_{c d}$ (Li et al., 2014). In the ApeSOD of $A$. pernix K1, it was hypothesized that the Fe-bound mode could mimic the product-inhibited form by residue Tyr39, and was proposed as an explanation for the lower activity of Fe/SOD than Mn/SOD (Nakamura et al., 2011). Therefore, we suspected that the binding mode of metal cofactors in AaSOD was similar as those SODs, in which $\mathrm{Fe}^{2+}$ competitively binds to the catalytic sites and thus restrains the activities of these cambialistic SODs. Therefore, it would be significantly beneficial to the SOD activity when we created an $\mathrm{Mn}^{2+}$-enriched environment for the expression of these Fe/Mn SODs, as our observations of high SOD activity in the $\mathrm{Mn}^{2+}$-enriched medium of this study.

Metal fidelity of AaSOD was further investigated by an in vitro reconstitution experiment with $1 \mathrm{mM} \mathrm{MnSO}_{4}$ and(or) $\mathrm{FeSO}_{4}$. As a result, the metal specificities were highly consistent with corresponding proteins expressed in the $\mathrm{MnSO}_{4}$ or $\mathrm{FeSO}_{4}$ enriched medium. As shown in Table 1, the specific activities of all treatments displayed higher activities than the apo-enzyme. The AaSOD sample that was reconstituted exclusively in the presence of $\mathrm{Fe}^{2+}$ had lower specific activity of $21.05 \mathrm{U} \mathrm{mg}^{-1}$, which was higher than the apo-enzyme while being lower than native AaSOD (90.94 $\mathrm{U} \mathrm{mg}^{-1}$ ) expressed in the crude LB medium. Similarly, the $\mathrm{Mn}^{2+}$-bound form of AaSOD also exhibited a remarkably higher specific activity of $517.63 \mathrm{U}$ $\mathrm{mg}^{-1}$, while the reconstituted sample upon both ions obtained a decreased activity of $270.27 \mathrm{U} \mathrm{mg}^{-1}$.

\section{Thermo- and pH-Stabilities of AaSOD}

For industrial purpose, many enzymes are preferred to be processed into solid state, which could be realized by freeze drying or spray drying technology. In the case of freeze drying, the enzymes can preserve high activity under lower temperature. However, the large-scaled production is limited by its high energy consumption and processing cost. Thus, the spray drying process is more favorable and widely used. In addition, thermostable enzymes are often associated with robust resistance to harsh environments, including detergent, strong acid and alkali, or chemical and denaturants (Vieille and Zeikus, 2001). Therefore, thermostable SODs are of great interest and screened as good candidates for industrial production. As we previously described, to explore excellent SODs for industrial

TABLE 1 | Superoxide dismutase (SOD) activity incorporating various ions.

\section{Sample} Specific activity $\left(\mathrm{U} \cdot \mathrm{mg}^{-1}\right)$
Natural medium

AaSOD from $\mathrm{Fe}^{2+}$ enriched medium

AaSOD from $\mathrm{Mn}^{2+}$ enriched medium

AaSOD from $\mathrm{Fe}^{2+}$ and $\mathrm{Mn}^{2+}$ enriched medium

Apo-enzyme

$\mathrm{Fe}^{2+}$-reconstitution

$\mathrm{Mn}^{2+}$ - reconstitution

$\mathrm{Fe}^{2+} / \mathrm{Mn}^{2+}$ - reconstitution
$90.94 \pm 0.47$

$74.65 \pm 2.92$

$1198.55 \pm 20.36$

$534.56 \pm 27.33$

$5.50 \pm 0.40$

$21.05 \pm 1.10$

$517.63 \pm 48.35$

$270.27 \pm 127.83$
The apo-enzyme was prepared by dialyzing the purified AaSOD with $50 \mathrm{mM}$ acetate buffer ( $p H$ 3.8) containing $8 \mathrm{M}$ urea and 10 mM EDTA. 

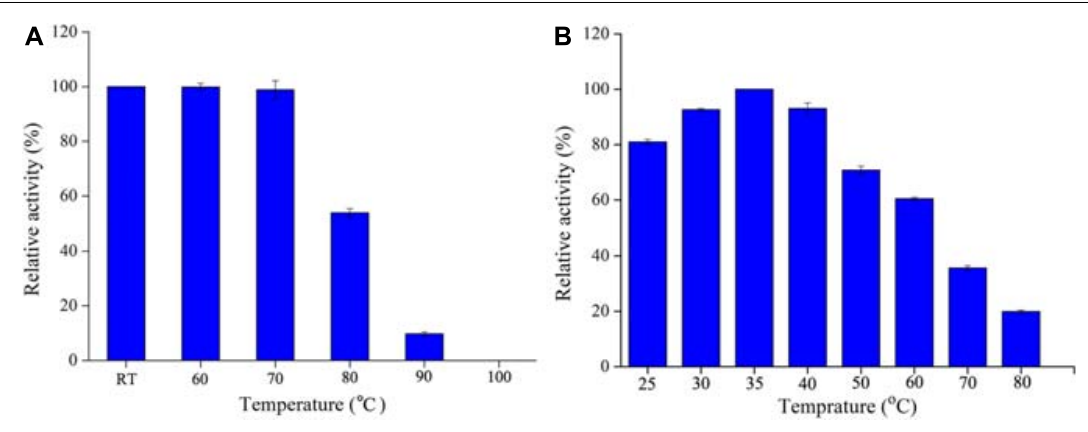

FIGURE 5 | Thermostability (A) and optimal temperature (B) of AaSOD. For thermostability measurement, the purified AaSOD was incubated at different temperatures $\left(\mathrm{RT}, 60,70,80,90\right.$, and $\left.100^{\circ} \mathrm{C}\right)$ for $1 \mathrm{~h}$, and subsequently measured the residual activities. The relative activity was calculated as the percentage of the maximum activity at $35^{\circ} \mathrm{C}$. To achieve the optimal catalytic temperature, the activity of purified AaSOD was tested at different temperatures $\left(25-80^{\circ} \mathrm{C}\right)$ and the highest activity was set as $100 \%$ for relative activity calculation.

application, some thermostable SODs had been identified from thermophilic strains. Alicyclobacillus sp. HJ is a strain from hotspring and possesses thermoacidophilic properties, i.e., grows optimally at $\mathrm{pH} 4.0$ and $65^{\circ} \mathrm{C}$. Therefore, it was regarded as an ideal source of thermostable or acid stable proteins, as our previous observation on a thermoacidophilic $\alpha$-amylase (Zhang et al., 2018). Expectedly, AaSOD exhibited high stability under high temperatures, with whole activity retaining after incubation at $60-70^{\circ} \mathrm{C}$ for $1 \mathrm{~h}$ (Figure 5A). In addition, 52.7\% activity was still detected after incubation at $80^{\circ} \mathrm{C}$ for $1 \mathrm{~h}$. Despite of robust thermostability, the optimal catalytic temperature of AaSOD is mesophilic. During a range of temperatures of $20-70^{\circ} \mathrm{C}$, the highest activity was observed at $35^{\circ} \mathrm{C}$ (Figure 5B). This is different from many SODs from thermopiles, which generally possess an optimum activity at high temperature (Seatovic et al., 2004; Zhu et al., 2013).

By directly measuring the forces stabilizing the conformational structure, DSC analysis is ideally suitable to evaluate protein thermal denaturation (Singh and Singh, 2004). Hence, the thermal denaturation of AaSOD was further measured with DSC analysis, by scanning from 70 to $120^{\circ} \mathrm{C}$ based on the purified AaSOD. After processes of buffer correction, normalization, and baseline subtraction, the DSC curve was fitted by the Gauss function (Figure 6). In the meanwhile, the melting temperature $\left(T_{m}\right)$ was calculated as $89.5^{\circ} \mathrm{C}$ and the $\Delta H$ value was $-2097 \mathrm{cal} \mathrm{mol}^{-1}$. This denaturation temperature is somewhat higher than the incubation temperature, of which the maximal activity was observed (Figure 5B). To our best knowledge, the thermophilic SODs are generally active at high temperatures, e.g., SOD_ASAC from Acidilobus saccharovorans has an optimal activity at $70^{\circ} \mathrm{C}$ and denaturation temperature of $107.3^{\circ} \mathrm{C}$ (Slutskaya et al., 2012). Due to their vast bioavailability of SODs, they are widely used in cosmetics and food additives, as well as in pharmaceuticals (Bafana et al., 2011). Compared to the recorded thermostable or themophilic SODs, the thermostable but mesophilic properties of AaSOD not only meet the requirement for the processing technology, but also endow its advantage to keep full functions after being taken into the organisms.

To date, available methods for measuring SOD activity are almost based on inhibitive assay, which are seriously restricted

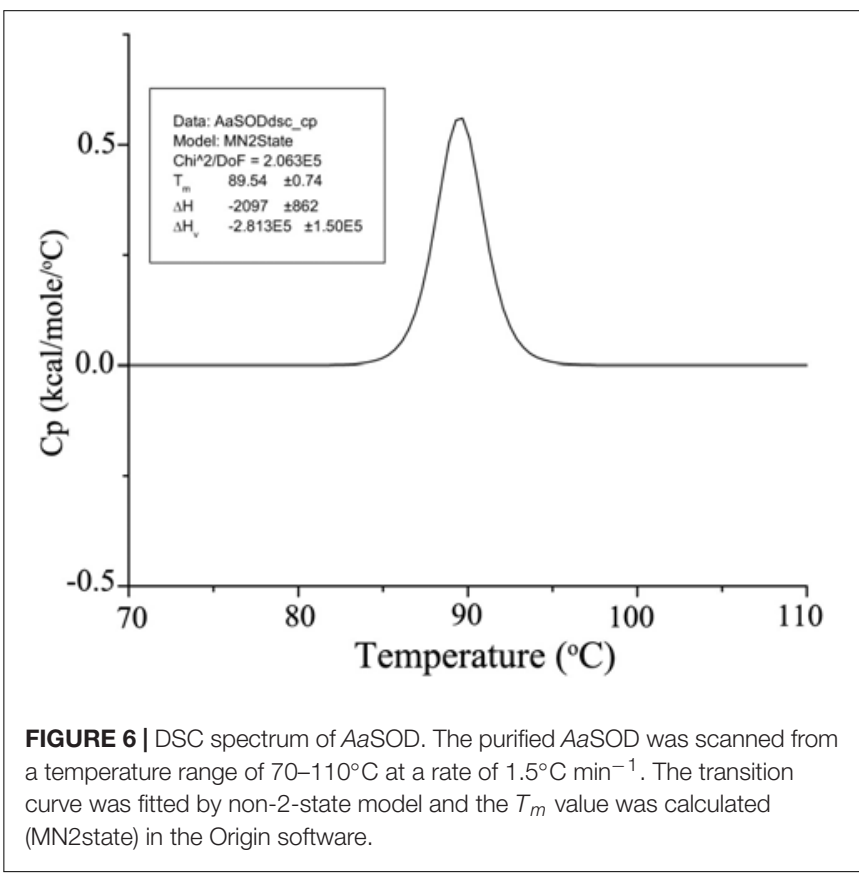

to the reaction $\mathrm{pH}$. Not unexpectedly, we failed to measure the acidic activities of $A a S O D$, even at $\mathrm{pH} 6.0$ conditions (data not shown). Therefore, we only tested the $\mathrm{pH}$ tolerance profiles by incubating the enzyme in various $\mathrm{pH}$ buffers for $1 \mathrm{~h}$. Using this maximum activity as $100 \%$, the relative activities of those proteins incubating in other $\mathrm{pH}$ buffers were calculated and shown in Figure 7A. Inspiringly, the enzyme showed good stability under a broad range of $\mathrm{pH}$ conditions with the highest stability at $\mathrm{pH}$ 4.0. In particular, it retained attractively high activities at extremely acidic conditions, with around 70 and $60 \%$ activities retained at $\mathrm{pH} 3.0$ and 2.0, respectively. This provides compelling evidence that $A a S O D$ is an acidophilic enzyme, which is in accordance to our previously observations, that the $\alpha$-amylase from strain Alicyclobacillus sp. $\mathrm{HJ}$ is also highly active at $\mathrm{pH} 4.0$ (Zhang et al., 2018). To our best knowledge, no recorded SOD showing such extremely acidic 

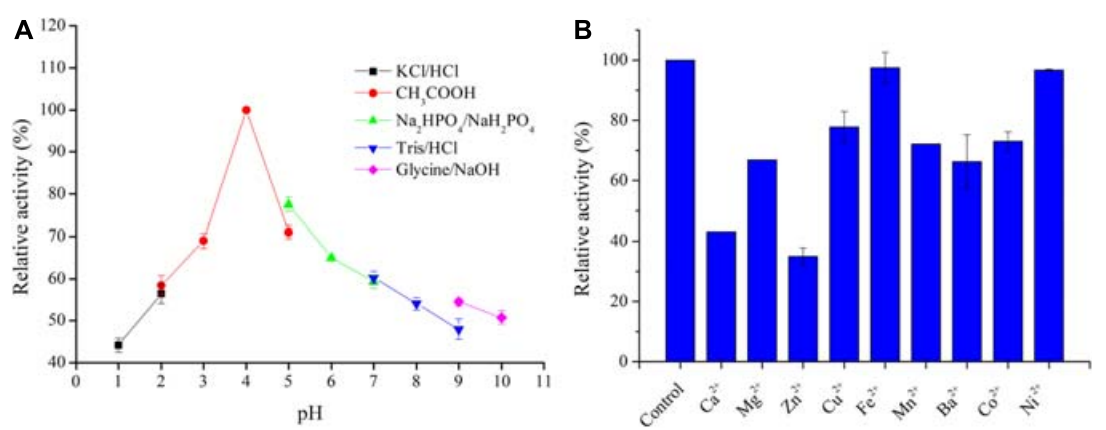

FIGURE 7 | Stabilities of AaSOD in buffers with different pH values (A) and effect of divalent ions on the AaSOD activity (B). The purified enzyme was incubated in the buffer systems of $200 \mathrm{mM} \mathrm{KCl-HCl} \mathrm{buffer} \mathrm{(pH} \mathrm{1.0-2.0),} \mathrm{acetate} \mathrm{buffer} \mathrm{(pH} \mathrm{2.0-5.0),} \mathrm{sodium} \mathrm{phosphate} \mathrm{buffer} \mathrm{(pH} \mathrm{5.0-7.0),} \mathrm{Tris-HCl} \mathrm{buffer} \mathrm{(pH} \mathrm{7.0-9.0),} \mathrm{and}$ glycine- $\mathrm{NaOH}$ buffer ( $\mathrm{pH} 9.0-10.0)$ for $1 \mathrm{~h}, 25^{\circ} \mathrm{C}$. The maximal activity was taken as $100 \%$ for relative activity calculation. For metal ions effects, the purified enzyme was incubated with $1 \mathrm{mM}$ of divalent metal ions in $50 \mathrm{mM}$ Tris- $\mathrm{HCl}$ buffer $(\mathrm{pH} 8.0)$, at $25^{\circ} \mathrm{C}$ for 30 min. The mixture with no ions supplementation was used as a control for relative activity calculation.

tolerance so far, and thus AaSOD would be served as an ideal model protein for exploring the mechanism of acidic tolerance. Moreover, abundant studies concluded that exogenous SOD supplementation has pharmacological and therapeutic benefits to mammals, including reduce liver oxidative stress in diabetic animals, resist inflammatory diseases, boost antioxidant defense and so on (Stephenie et al., 2020). Consequently, being an oral medicine or dietary supplement would be a favorable form for SOD administration. Regarding the advantage of excellent acidic tolerance, AaSOD will be stable in the stomach after being digested by the organisms, and thus assure its activity as food additive and for medicine use.

\section{Influence of Divalent lons on AaSOD Activity}

As shown in Figure $\mathbf{7 B}$, various divalent metal ions were supplemented into the reaction mixture and tested for their influence on the catalytic activity of purified AaSOD. As a result, the SOD activities were partly suppressed by some tested metal ions. However, still more than $60 \%$ activities were reserved upon tested metal ions, with exceptions of $\mathrm{Zn}^{2+}$ and $\mathrm{Ca}^{2+}$. As shown in Figure 7B, only around $40 \%$ activity was preserved in the presence of $1 \mathrm{mM}$ of $\mathrm{Zn}^{2+}$. Differently, $\mathrm{Fe}^{2+}$ and $\mathrm{Ni}^{2+}$ showed no influence on the enzymatic activity, with the activity retained completely upon $\mathrm{Fe}^{2+}$ and $96.7 \%$ in the presence of $1 \mathrm{mM}$ $\mathrm{Ni}^{2+}$. These results are mostly in agreement with the Mn-SOD from Geobacillus sp. EPT3, in which most metal ions except $\mathrm{Mn}^{2+}$ partially inhibited the enzyme activities but not lethal (Zhu et al., 2014). This guarantee high activities of these SODs when exposing to trace metal ions in applications.

\section{CONCLUSION}

This manuscript firstly describes one thermostable and cambialistic SOD from a thermoacidophilic Alicyclobacillus strain. There are ample potentials in various applications with its advantages: it is significantly active in the mesophilic environment but highly stable under high temperatures, and it is an acidophilic protein with high stability at extremely acidic environments. Its large amount of heterologous expression and superior activity in the presence of $\mathrm{Mn}^{2+}$ create great feasibility for its industrial scale producing. Future studies would focus on optimizing its large-scaled expression and purifications protocols, achieving exogenous expression in the biosafety strain like $B$. subtilis, as well as experimentally testing its bioactivity and bioavailability in the animal models.

\section{DATA AVAILABILITY STATEMENT}

The nucleotide sequence encoding AaSOD was deposited in the GenBank database, accession number LC573735. The Strain Alicyclobacillus sp. HJ was deposited in the Marine Culture Collection of China, accession number MCCC 1K03506.

\section{AUTHOR CONTRIBUTIONS}

$\mathrm{CY}$ and $\mathrm{XD}$ conceptualized and defined the experimental design. $\mathrm{XD}, \mathrm{WW}, \mathrm{HH}$, and SL performed the experiments. $\mathrm{CY}, \mathrm{HH}$, and PL carried out the data analysis and manuscript preparation. All authors contributed to the article and approved the submitted version.

\section{FUNDING}

This study was supported by the financial supports from the National Natural Science Foundation of China (31870094) and Collaborative Innovation Project of Shandong Academy of Science (2019-CXY9).

\section{ACKNOWLEDGMENTS}

The authors thank Jingyao Qu and Zhifeng Li for the technical help in DSC analysis. 


\section{REFERENCES}

Abreu, I. A., and Cabelli, D. E. (2010). Superoxide dismutases-a review of the metal-associated mechanistic variations. Biochim. Biophys. Acta 1804, 263-274. doi: 10.1016/j.bbapap.2009.11.005

Adams, J. J., Morton, C. J., and Parker, M. W. (2019). The crystal structure of the manganese superoxide dismutase from Geobacillus stearothermophilus: Parker and Blake (1988) revisited. Aust. J. Chem. 73, 145-150. doi: 10.1071/ch19346

Amo, T., Atomi, H., and Imanaka, T. (2003). Biochemical properties and regulated gene expression of the superoxide dismutase from the facultatively aerobic hyperthermophile Pyrobaculum calidifontis. J. Bacteriol. 185, 6340-6347. doi: 10.1128/jb.185.21.6340-6347.2003

Bafana, A., Dutt, S., Kumar, S., and Ahuja, P. S. (2011). Superoxide dismutase: an industrial perspective. Crit. Rev. Biotechnol. 31, 65-76. doi: 10.3109/07388551. 2010.490937

Bai, Y., Wang, J., Zhang, Z., Shi, P., Luo, H., Huang, H., et al. (2010). A novel family $9 \beta-1,3(4)$-glucanase from thermoacidophilic Alicyclobacillus sp. A4 with potential applications in the brewing industry. Appl. Microbiol. Biotechnol. 87, 251-259. doi: 10.1007/s00253-010-2452-3

Boyadzhieva, I. P., Atanasova, M., and Emanuilova, E. (2010). A novel, thermostable manganese-containing superoxide dismutase from Bacillus licheniformis. Biotechnol. Lett. 32, 1893-1896. doi: 10.1007/s10529-010-0368-8

Bradford, M. (1976). A rapid and sensitive method for the quantitation of microgram quantities of protein utilizing the principle of protein-dye binding. Anal. Biochem. 72, 248-254. doi: 10.1016/0003-2697(76)90527-3

Carlioz, A., Ludwig, M. L., Stallings, W. C., Fee, J. A., and Touati, D. (1988). Iron superoxide dismutase nucleotide sequence of the gene from Escherichia coli K12 and correlations with crystal structures. J. Biol. Chem. 263, 1555-1562. doi: 10.1016/s0021-9258(19)57340-9

Correa-Llantén, D. N., Amenábar, M. J., Muñoz, P. A., Monsalves, M. T., Castro, M. E., and Blamey, J. M. (2014). Alicyclobacillus sp. strain CC2, a thermoacidophilic bacterium isolated from Deception Island (Antarctica) containing a thermostable superoxide dismutase enzyme. Adv. Polar Sci. 25, 92-96.

Emerit, J., Samuel, D., and Pavio, N. (2006). Cu-Zn super oxide dismutase as a potential antifibrotic drug for hepatitis $\mathrm{C}$ related fibrosis. Biomed. Pharmacother. 60, 1-4. doi: 10.1016/j.biopha.2005.09.002

He, Y. Z., Fan, K. Q., Jia, C. J., Wang, Z. J., Pan, W. B., Huang, L. Y., et al. (2007). Characterization of a hyperthermostable Fe superoxide dismutase from hot spring. Appl. Microbiol. Biotechnol. 75, 367-376. doi: 10.1007/s00253-0060834-3

Hunter, T., Bonetta, R., Sacco, A., Vella, M., Sultana, P. M., Trinh, C. H., et al. (2018). A single mutation is sufficient to modify the metal selectivity and specificity of a eukaryotic manganese superoxide dismutase to encompass iron. Chem. Eur. J. 24, 5303-5308. doi: 10.1002/chem.201704655

Jackson, S. M. J., and Cooper, J. B. (1998). An analysis of structural similarity in the iron and manganese superoxide dismutases based on known structures and sequences. Biometals 11, 159-173.

Johnson, F., and Giulivi, C. (2005). Superoxide dismutases and their impact upon human health. Mol. Aspects Med. 26, 340-352. doi: 10.1016/j.mam.2005.07.006

Ken, C. F., Hsiung, T. M., Huang, Z. X., Juang, R. H., and Lin, C. T. (2005). Characterization of Fe/Mn-superoxide dismutase from diatom Thallassiosira weissflogii: cloning, expression, and property. J. Agric. Food Chem. 53, 14701474. doi: 10.1021/jf048269f

Kumar, S., Stecher, G., and Tamura, K. (2016). MEGA7: molecular evolutionary genetics analysis version 7.0 for bigger datasets. Mol. Biol. Evol. 33, 1870-1874. doi: 10.1093/molbev/msw054

Lah, M. S., Dixon, M. M., Pattridge, K. A., Stallings, W. C., and Ludwig, M. L. (1995). Structure-function in Escherichia coli iron superoxide dismutase: comparisons with the manganese enzyme from Thermus thermophilus. Biochemistry 34, 1646-1660. doi: 10.1021/bi00005a021

Lancaster, V. L., LoBrutto, R., Selvaraj, F. M., and Blankenship, R. E. (2004). A cambialistic superoxide dismutase in the thermophilic photosynthetic bacterium Chloroflexus aurantiacus. J. Bacteriol. 186, 3408-3414. doi: 10.1128/ jb.186.11.3408-3414.2004

Lee, B. D., Apel, W. A., Sheridan, P. P., and Deveaux, L. C. (2018). Glycoside hydrolase gene transcription by Alicyclobacillus acidocaldarius during growth on wheat arabinoxylan and monosaccharides: a proposed xylan hydrolysis mechanism. Biotechnol. Biofuels 11:110.
Li, D. C., Gao, J., Li, Y. L., and Lu, J. A. (2005). Thermostable manganesecontaining superoxide dismutase from the thermophilic fungus Thermomyces lanuginosus. Extremophiles 9, 1-6. doi: 10.1007/s00792-004-0413-4

Li, H., Feng, Z. M., Sun, Y. J., Ning, S. J., Zhou, W. L., Liu, A., et al. (2016). Engineering a thermostable iron superoxide dismutase based on manganese superoxide dismutase from Thermus thermophilus. Process Biochem. 51, 39-47. doi: 10.1016/j.procbio.2015.11.001

Li, M., Guo, S., Li, X., Wang, Q., and Wang, W. (2017). Engineering a highly thermostable and stress tolerant superoxide dismutase by $\mathrm{N}$-terminal modification and metal incorporation. Biotechnol. Bioprocess Eng. 22, 725-733. doi: 10.1007/s12257-017-0243-8

Li, W., Wang, H., Chen, Z., Ye, Q., Tian, Y., Xu, X., et al. (2014). Probing the metal specificity mechanism of superoxide dismutase from human pathogen Clostridium difficile. Chem. Commun. 50, 584-586. doi: 10.1039/c3cc47859a

Liu, P., Ewis, H. E., Huang, Y. J., Lu, C. D., Tai, P. C., and Weber, I. T. (2007). Structure of Bacillus subtilis superoxide dismutase. Acta Crystallogr. F. Struct. Biol. Cryst. Commun. 63, 1003-1007.

López, G., Díaz-Cárdenas, C., Alzate, J. D., Gonzalez, L. N., and Baena, S. (2018). Description of Alicyclobacillus montanus sp. nov. a mixotrophic bacterium isolated from acidic hot springs. Int. J. Syst. Evol. Microbiol. 68, 1608-1615. doi: 10.1099/ijsem.0.002718

Mandelli, F., Franco Cairo, J. P. L., Citadini, A. P. S., Mandelli, F., Alvarez, T. M., Oliveira, R. J., et al. (2013). The characterization of a thermostable and cambialistic superoxide dismutase from Thermus filiformis. Lett. Appl. Microbiol. 57, 40-46. doi: 10.1111/lam.12071

Manolov, V., Yonova, D., Bogov, B., Petrova, J., Vasilev, V., and Vazelov, E. (2017). Hepcidin, selenium and superoxide dismutase in oxidative stress and in dialysis patients. J. Urol. Nephrol. 2:000116.

Marklund, S. L., and Marklund, G. (1974). Involvement of the superoxide anion radical in the autoxidation of pyrogallol and a convenient assay for superoxide dismutase. Eur. J. Biochem. 47, 469-474. doi: 10.1111/j.1432-1033.1974. tb03714.x

Matès, J. M., and Sánchez-Jimènez, F. (2000). Role of active oxygen species in apoptosis: implications for cancer therapy. Int. J. Biochem. Cell. Biol. 32, 157-170. doi: 10.1016/s1357-2725(99)00088-6

McKnight, I. C., Eiroa, M. N., Sant, A. S., and Massaguer, P. R. (2010). Alicyclobacillus acidoterrestris in pasteurized exotic Brazilian fruit juices: isolation, genotypic characterization and heat resistance. Food Microbiol. 27, 1016-1022. doi: 10.1016/j.fm.2010.06.010

Meier, B., Barra, D., Bossa, F., Calabrese, L., and Rotilio, G. (1982). Synthesis of either $\mathrm{Fe}$ - or Mn-superoxide dismutase with an apparently identical protein moiety by an anaerobic bacterium dependent on the metal supplied. J. Biol. Chem. 257, 13977-13980. doi: 10.1016/s0021-9258(19)45329-5

Miller, A. F. (2012). Superoxide dismutases: ancient enzymes and new insights. FEBS Lett. 586, 585-595. doi: 10.1016/j.febslet.2011.10.048

Morozkina, E. V., Slutskaya, E. S., Fedorova, T. V., Tugay, T. I., Golubeva, L. I., and Korolev, O. V. (2010). Extremophilic microorganisms: biochemical adaptation and biotechnological application (Review). Appl. Biochem. Microbiol. 46, 1-14. doi: $10.1134 /$ s0003683810010011

Nakamura, T., Nakamura, T., Torikai, K., Uegaki, K., Morita, J., Machida, K., et al. (2011). Crystal structure of the cambialistic superoxide dismutase from Aeropyrum pernix $\mathrm{K} 1$-insights into the enzyme mechanism and stability. FEBS J. 278, 598-609. doi: 10.1111/j.1742-4658.2010.07977.x

Naso, F. C. D., Dias, A. S., Porawski, M., and Marroni, N. A. P. (2011). Exogenous superoxide dismutase: action on liver oxidative stress in animals with streptozotocin-induced diabetes. Exp. Diabetes Res. 2011:754132.

Perry, J. J. P., Shin, D. S., Getzoff, E. D., and Tainer, J. A. (2010). The structural biochemistry of the superoxide dismutases. Biochim. Biophys. Acta 1804, 245-262.

Schmidt, M., Meier, B., and Parak, F. (1996). X-ray structure of the cambialistic superoxide dismutase from Propionibacterium shermanii active with Fe or Mn. J. Biol. Inorg. Chem. 1, 532-541. doi: 10.1007/s007750050089

Seatovic, S., Gligic, L., Radulovic, Z., and Jankov, R. M. (2004). Purification and partial characterization of superoxide dismutase from the thermophilic bacteria Thermothrix sp. J. Serb. Chem. Soc. 69, 9-16. doi: 10.2298/jsc0401009s

Singh, S., and Singh, J. (2004). Controlled release of a model protein lysozyme from phase sensitive smart polymer systems. Inter. J. Pharm. 271, 189-196. doi: 10.1016/j.ijpharm.2003.11.010 
Slutskaya, E. S., Bezsudnova, E. Y., Mardanov, A. V., Safenkova, I. V., Kleimenov, S. Y., Chebotareva, N. A., et al. (2012). Iron-dependent superoxide dismutase from novel thermoacidophilic crenarchaeon Acidilobus saccharovorans: from gene to active enzyme. Biochemistry 77, 1368-1376. doi: $10.1134 / \mathrm{s} 0006297912120048$

Song, N. N., Zheng, Y., E, S. J., and Li, D. C. (2009). Cloning, expression, and characterization of thermostable manganese superoxide dismutase from Thermoascus aurantiacus var. levisporus. J. Microbiol. 47, 123-130. doi: 10. 1007/s12275-008-0217-9

Steinman, H. M. (1978). The amino acid sequence of Mangano superoxide dismutase from Escherichia coli B. J. Biol. Chem. 253, 8708-8720. doi: 10.1016/ s0021-9258(17)34235-7

Stephenie, S., Chang, Y. P., Gnanasekaran, A., Esa, N. M., and Gnanaraj, C. (2020). An insight on superoxide dismutase (SOD) from plants for mammalian health enhancement. J. Funct. Foods 68, 103917. doi: 10.1016/j.jff.2020.103917

Trotti, A. (1997). Toxicity antagonists in cancer therapy. Curr. Opin. Oncol. 9, 569-578. doi: 10.1097/00001622-199711000-00013

Vieille, C., and Zeikus, G. J. (2001). Hyperthermophilic enzymes: sources, uses, and molecular mechanisms for thermostability. Microbiol. Mol. Biol. Rev. 65, 1-43. doi: $10.1128 / \mathrm{mmbr} .65 .1 .1-43.2001$

Waterhouse, A., Bertoni, M., Bienert, S., Studer, G., Tauriello, G., Gumienny, R., et al. (2018). SWISS-model: homology modelling of protein structures and complexes. Nucleic. Acids. Res. 46, 296-303.

Yamano, S., Sako, Y., Nomura, N., and Maruyama, T. (1999). A cambialistic SOD in a strictly aerobic hyperthermophilic archaeon, Aeropyrum pernix. J. Biochem. 126, 218-225. doi: 10.1093/oxfordjournals.jbchem.a022426
Zhang, B., Wu, Y. F., Song, J. L., Huang, Z. S., and Jiang, C. Y. (2015). Alicyclobacillus fodiniaquatilis sp. nov, isolated from acid mine water. Int. J. Syst. Evol. Microbiol. 65, 4915-4920. doi: 10.1099/ijsem.0. 000695

Zhang, L., Yin, H., Zhao, Q., Yang, C., and Wang, Y. (2018). High alkaline activity of a thermostable $\alpha$-amylase (cyclomaltodextrinase) from thermoacidophilic Alicyclobacillus isolate. Ann. Microbiol. 68, 811-888.

Zhu, H., Liu, J., Qu, J., Gao, X., and Lu, J. R. (2013). Stress fermentation strategies for the production of hyperthermostable superoxide dismutase from Thermus thermophilus HB27: effects of ions. Extremophiles 17, 995-1002. doi: 10.1007/ s00792-013-0581-1

Zhu, Y., Wang, G., Ni, H., Xiao, A., and Cai, H. (2014). Cloning and characterization of a new manganese superoxide dismutase from deep-sea thermophile Geobacillus sp. EPT3. World J. Microbiol. Biotechnol. 30, 13471357. doi: $10.1007 /$ s11274-013-1536-5

Conflict of Interest: The authors declare that the research was conducted in the absence of any commercial or financial relationships that could be construed as a potential conflict of interest.

Copyright $\odot 2021$ Dong, Wang, Li, Han, Lv and Yang. This is an open-access article distributed under the terms of the Creative Commons Attribution License (CC BY). The use, distribution or reproduction in other forums is permitted, provided the original author(s) and the copyright owner(s) are credited and that the original publication in this journal is cited, in accordance with accepted academic practice. No use, distribution or reproduction is permitted which does not comply with these terms. 